\title{
http://jaet.journals.ekb.eg \\ INFLUENCE OF PHASE CHANGE MATERIALS (PCMs) ON POLYURETHANE (PU) FOAM FIRE-RETARDANCY
}

\author{
Adham M. Mohammed ${ }^{1}$, Abdel Monteleb M. Aly ${ }^{1}$,Amira Elnokaly ${ }^{2}$ and Mohamed H. Mahmoud \\ ${ }^{I}$ Department of Architecture, Faculty of Engineering, University of Assuit, Egypt \\ ${ }^{2}$ School of Architecture and the Built Environment, University of Lincoln, UK
}

\begin{abstract}
:Polyurethane (PU) foam is a material that has long been regarded as a good thermal insulator for building purposes due to many advantageous attributes, such as cost and feasibility. Yet, to further develop its performance, many studies have focused on the potential of using the micro-structure of PU foam as an encapsulation for PCMs. Despite the apparent advantageous outcome of this premise, from the perspective of thermal performance, fire-retardancy issues may pose as a threat. PU foam is known for its inherent poor fire-retardation properties. With the addition of PCMs, especially waxbased, it is possible that the fire-retardancy would worsen. This would translate into additional costs in terms of application of treatments to counter the disadvantageous hazardous properties. In this study,an empirical investigation is carried out with the aim of determining whether addition PCMs to PU foam would influence its retardation, and to which extent.In this context, granules of wax-based PCMs are encapsulated in to closed-cell rigid PU foam via a simplified amalgamation method. Two concentrations of PCM content are presented in this paper. Then, fire-retardancy testing is performed on specimens to compare the performance of the created PU/PCM specimens with this of regular PU specimens. The outcome of this empirical investigationfurther confirms that addition of PCM to PU foam is disadvantageous in terms of fire-retardancy, and that the amount of added PCM is of considerable influence on this.
\end{abstract}

Keywords:Polyurethane foam; Phase change materials; PCM encapsulation; simple amalgamation; Fire-retardancy; Pace of ignition.

\section{INTRODUCTION}

PU foam is a material that is widely accepted as a suitable thermal insulation for building envelopes. Many utilize such material as it is of relatively low-cost, with worldwide prices as low as $\$ 0.8$ per $\mathrm{kg}$ [1] and $\$ 200$ per $^{3}[2]$. Furthermore, it is available in numerous forms, such as thermal insulation panels and PU foam spray, which optimally addresses commercial needs. Figure 1(A) shows an example of a commercially available sandwich panel containing PU foam from TOPOLO inc., where Figure 1(B) shows commercial PU foam panels from Focus Technology Co., Ltd.PU foams also are easy to install and require little skill or training to manage. Figure 1(C) shows PU foam easily applied to a wall through a spray method and Figure 1(D) presents application of spray PU foam to the ceiling of a building in Egypt by ETC $^{\circledR}$.Despite this, PU foam is inherently flammable[3-5], which has been the main cause for many tragic fire incident around the world that have been attributed to usage of PF foam, such as the incidents in residential buildings in China and the UK, shown in Figure $1(\mathrm{E} \& \mathrm{~F})$. This requires manufacturers to utilize several methods to limit Received:23 July, 2020, Accepted: 5 July ,2020 such negative attribute to allow for PU foam to be safely used within buildings and comply with building regulation. It is worthy to note that many international standards have explicitly addressed PU foam flammability such as the UL94, IEC60695-1120, ISO9772 and ISO9773 standards.Literature shows that it is possible to reduce PU foam flammability by using certain additives and fillers[6-8,3]. The incipient nano-technology presents several superior solutions to this issue which have shown good potential in this regards $[9,10]$. Literature also shows that it is possible to use specific coatings that prevent the negative effect of flames of PU foam[11-16].To enhance the thermal performance of PU foam, however, literature has also presented several innovative ideas that include the use of PCMs as a sustainable material with little environmental impact.Attempts of incorporation of PCMs for within the matrix of PU foams have shown to be successful in terms of increasing insulation capabilities[17-25]. Various methods have been devised for this purpose such as direct amalgamation of PCMs and incorporation of polymer micro-encapsulated PCMs [17-25].It is worthy to note that other useful purposes such as thermal storage have been seen to benefit from such 
incorporation[26-29]. This approach has proven to be promising from the perspective of thermal performance.However, many PCMs are inherently flammable, especially in the case of wax-based PCMs such as paraffin wax, which seems to be of interest to many due to other advantageous characteristics. It is possible that the combination of PU foam and wax-based PCM would create a highly flammable material that is unusable if untreated. The present study primarily aims at investigating the degree to which PU foam flameretardation can be influenced by addition of PCMs, in addition to highlighting the possible effect of increasing/decreasing the concentration of PCM in the PU matrix.The mentioned aim presents a novelty in research as, to the authors knowledge, little or no research has focused on fire-retardation effects of PCM incorporation with PU foam, despite the extensive research pertaining to the thermal influence of such process. As such, a simplified amalgamation method is used to create panels of PCM encapsulated within PU foam. Two concentrations of PCM content are created. Then, samples of the created panels are tested for their fire-retardation properties. The aim is to explore the degree PU foam can be influenced by PCMs and determine the effect of the PCM amount. It is worthy to note that it is not the goal of the present study to provide official fire-retardation classifications for the created materials, rather, compare the properties of regular PU foam with PCM-enhanced PU foam. It is worthy to also recognize that regardless of the disadvantageous flammability influence that PCMs may have on PU foam, it is most likely that fire-retardation treatments can counter this effect. Yet, consequently, worsened fire-retardation properties can translate to additional costs of manufacturing.
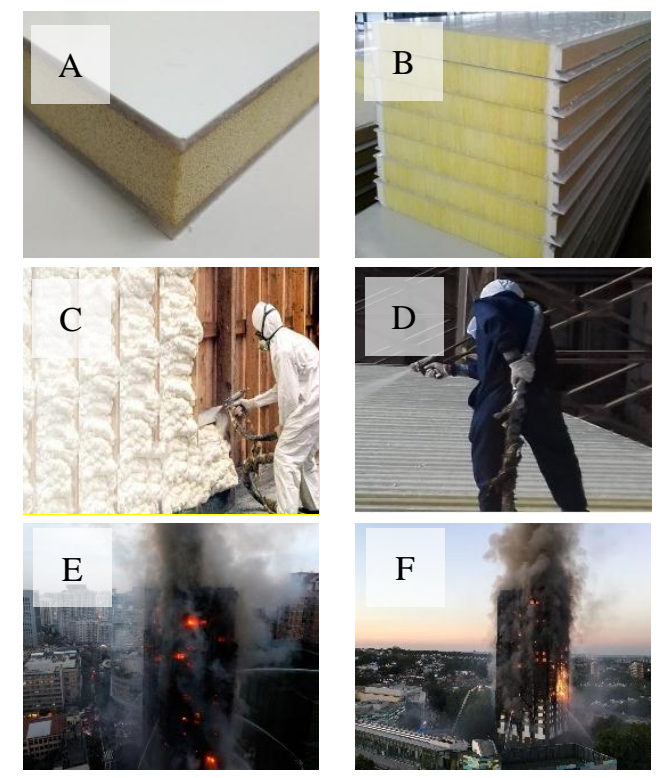

Figure 1: (A) Sandwich panels containing PU foam. (B) PU foam panels. (C) Spray PU foam application to walls. (D) Spray PU foam application to ceilings.(E) Incident in China. (F) Incident in the UK.

\section{MATERIAL AND SPECIMENS}

In the present study, closed-cell rigid Polyurethane (PU) foam is used as a form of encapsulation of the PCM. As presented in Figure 2, panels are created with different concentrations of PCMs, which are then cut to specimen size as guided by the UL-94 standard. The specimens are marked and cured in an environmental chamber then exposed to flames. The performance of the mentioned specimens under exposure to fire is compared with the purpose of determining the effect of PCM.

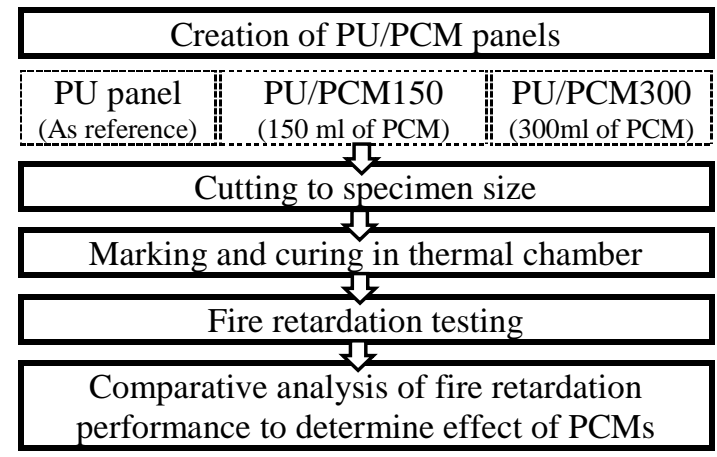

Figure 2: Methodology for determining the effect of PCM on fire-retardation.

In detail, acommercially-available type of

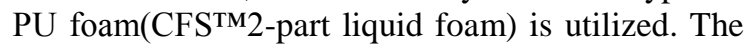
foam mixture entailed oftwocompounds, namely,Part A which is aPolymeric MDI and part B which contains Poly-etherols, flame-retardant, Silicone, Catalyst and Blowing agents, to be mixed withalmostequalvolume $\operatorname{ratio}(1: 1.06)$, as is instructed by the provider. The PCM used in the context of this study was Paraffin wax with a melting temperature of $43^{\circ} \mathrm{C}$. The PU foam mixture is mixed with frozen and ground granule of PCM, then, the mixture is poured into a secured mould where it begins to expand. An upper restraint (tile with weights) is placed immediately on the mould to ensure that the panel exhibits even surfaces and thickness. Figure 3(A) shows an example of the mentioned process for the creation of one of the examined panels. The upper restraint is removed after around 60 minutes of casting to ensure the complete solidification is attained. To investigate the performance of PU panels enhanced with PCMs three panels are created. A PU foam panel is created, used as a reference, and a PU panel containing an amount of $150 \mathrm{ml}$ of PCM, referred to as the PU/PCM150 panel. Also, a PU panel containing $300 \mathrm{ml}$ of PCM is created to investigate 
the effect of increasing the amount of PCM, referred to as the PU/PCM300 panel. All the created panels were of identical dimensions and of a volume of $400 \mathrm{~cm}^{3}$. SEM images of the panels were then taken to examine their micro-structure, which show that the PCM granules have been homogeneously dispersed in the PU foam without any PCM accumulations. Figure 3(B)shows the location of PCM granules dispersed in a sample of the panel. According to several SEM measurements, such as shown in Figure 3(C), the granule sizes of PCM inside the panel were confirmed to range from 0.10 to $0.25 \mathrm{~mm}$. The intermediate distance between the granules were found to range from 0.25 to 1.2 mm.Figure 3 (D\&E) show the panels containing PCM.

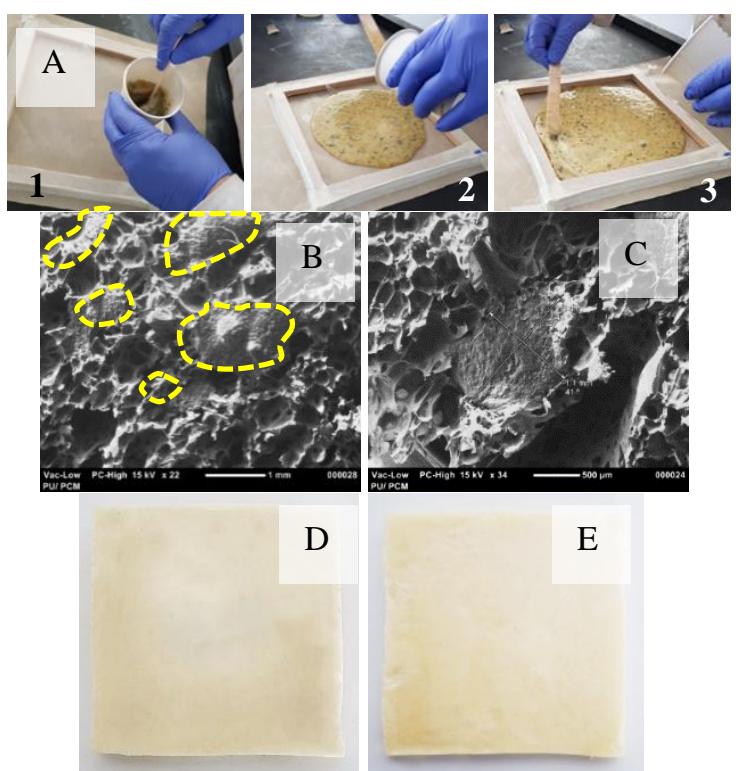

Figure 3: (A) Creation process of $\mathrm{PU} / \mathrm{pcm}$ foams. (B) SEM image showing the dispersion of PCM granules in a sample of PU/PCM panel. (C) Size of a single PCM granule. (D) PU/PCM150 panel. (E) PU/PCM300 panel.

To comply, where possible, with the specifications of the UL94-HBF, and in coherence with the ISO 9772, the ASTM D4986 and GB/t 8332 parameters, the tested specimens are determined to be of dimensions of $12.7 \mathrm{~mm}(0.5$ inches)* $127 \mathrm{~mm}$ (5 inches) with a thickness of 12.7 $\mathrm{mm}$ (0.5 inches). For each panel, a number of 5 specimens are extracted in addition to one auxiliary sample. The location of extraction of specimens from each panel was spread out within the entire panel.Figure 4(A)shows the locations of which the specimens are extracted in relation to the corresponding typical amalgam panel. The intermediate spacing between the specimens were $1.80 \mathrm{~cm}$, with an upper and lower distance from panel edges of $3.70 \mathrm{~cm}$. Figure $4(\mathrm{~B}, \mathrm{C} \& \mathrm{D})$ shows images of the extracted specimens. It may be seen that, due to cutting issues, some of the samples were not fine cut. However, the irregularities observed were not seen to be of significant influence as they were minimal in size, hence, no considerable effect to the volume of the tested sample has occurred.The extracted specimens are, according to the specifications, cured in an environmental chamber at a relative humidity of $50 \%$ for a duration of 2 days as a minimum. As required also, the extracted specimens are marked, using a non-corrosive marker, at both ends of each specimen at distances of $25.4 \mathrm{~mm}$ (1.0 inch) of each end. The marks, in blue, are to facilitate the timing of the spread of fire, in accordance with the mentioned standards. Additional markings, in green, are added to further ensure the accuracy of timing. Figure 4(E) shows an example of the mentioned marking on a specimen. It should be noted that the mentioned markings are referred to as $\mathrm{M}^{1}, \mathrm{M}^{2}, \mathrm{M}^{3}$ and $\mathrm{M}^{4}$.
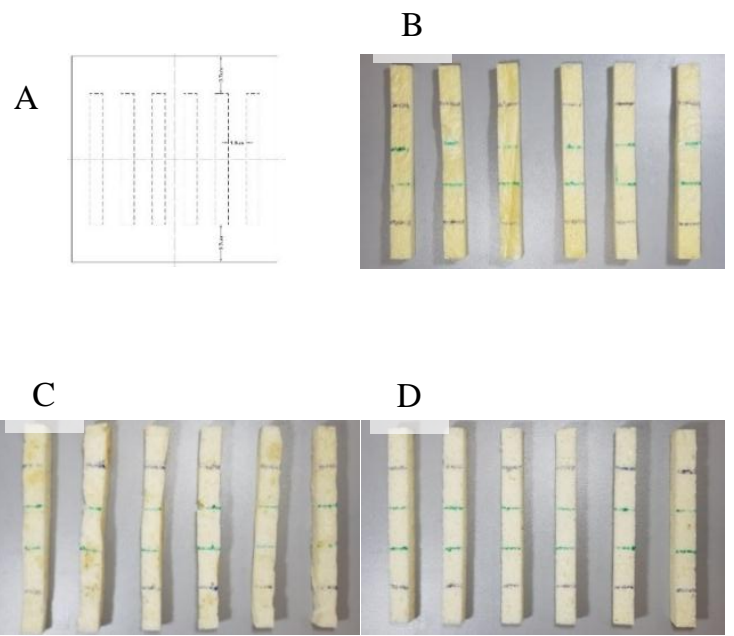

$\mathrm{E}$
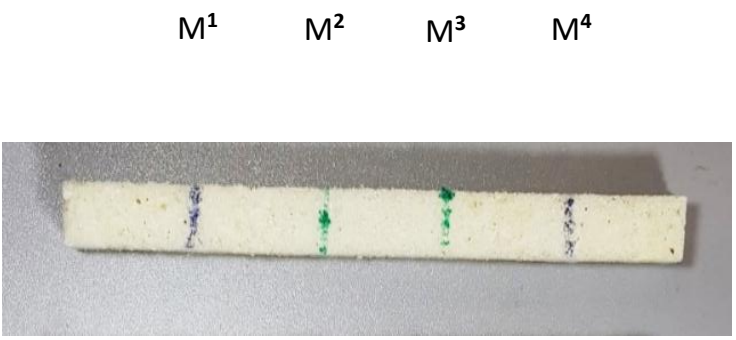

Figure 4: (A) Schematic showing the location of the extracted specimens in relation to the panel. (B) PU. (C) PU/PCM150. (D) PU/PCM300. (E) Markings, for timing. 


\section{EXPERIMENTAL SET-UP}

The experimental set-up entails of a holder fitted with rotatable clamps. The clamps are used to hold a wire gauge which acts as a try for the tested specimen to be placed on during ignition, in the course of testing. The wire gauge tray, shown inFigure 5(A), is made of $1 \mathrm{~mm}$ thick aluminium with dimensions of $76 \mathrm{~mm}$ ( 3 inches) $* 152 \mathrm{~mm}(6$ inches). An additional length was provided of 13 $\mathrm{mm}$ ( 0.5 inches approximately) that was folded to form a right-angle rim used to further secure the specimens once placed on the aluminium tray. To ignite the specimen, a Bunsen burner with a shaft length of $100 \pm 10 \mathrm{~mm}$ was used. The burner was secured at an angled position of $45^{\circ}$ to avoid possible dripping from the tested sample on the burner's nozzle which may affect the properties of the burning flame, hence, affecting the accuracy of the procedure. A metal tray of dimensions of $25 * 35$ $\mathrm{cm}$ was placed under the specimen holder which had contained an amount of cotton bedding, with the purpose of capturing possible ignited dripping from the tested specimen. Two timers were also used in the context of the procedure, a standard analogue timer in addition to a digital timer, both with an accuracy of 0.01 seconds. To capture images of the incineration process of the specimens, aFLIR ${ }^{\circledR} \mathrm{E} 8$ thermal imaging camera, mention earlier in detail, was set-up facing the specimen holder at a suitable distance. The mentioned apparatus was placed over fire-proof mats to avoid any fire hazards. Figure 5(B) shows in detail the components of the experimental set-up. It should be noted that the entire set-up was placed inside a Clean Air Ltd. fume hood, of a volume of greater than $0.5 \mathrm{~m}$, fitted with propane gas feed as can be seen in Figure 5(C).

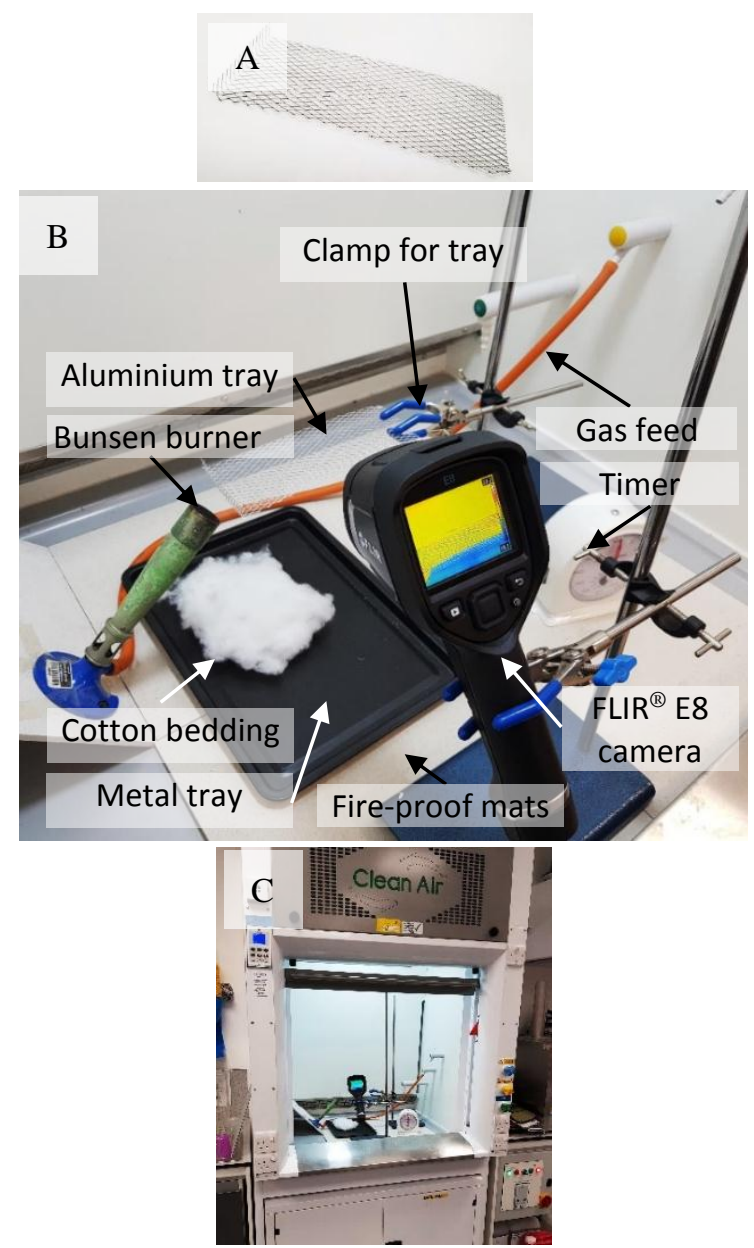

Figure 5: (A) Aluminium wire gauge try, as a specimen holder. (B) Experimental set-up. (C) Setup inside the Clean Air Ltd. fume hood.

\section{EXPERIMENTAL PROCEDURE}

The tested specimen is required to be ignited at one end for a specific duration of time, then the spread of fire is monitored in terms of the pace of spreading. The marks on the specimen are used to facilitate the mentioned process by showing the distance of spread against corresponding time. The length of the igniting flame of the Bunsen burner was set to the specified $38 \pm 2 \mathrm{~mm}$ blue flame length, as stated by the UL94 HBF standard. The specimen holder/tray was re-positioned so that the end of the tray was at a height of $10 \mathrm{~mm}$ from the center of the burner's nozzle. The tested specimen is then placed on the tray and rotated so allow for the end of the specimen to be in contact with the flame. After the specimen is exposed to the flame for the required time of either 60 seconds starting from the point of contact with the flame or until the burning section of the specimen reaches M1, the clamp that holds the tray is rotated again approximately $45^{\circ}$ to remove the tested specimen away from the flame. In this final position, the metal tray which holds the cotton bedding is located directly beneath the tray, holding the burning specimen, at an approximate distance of $17 \mathrm{~cm}$. Once the ignition of the 
specimen is complete, the timer is started. Also, a digital timer is started to ensure correct timing. Photographic and thermal images are taken every five seconds using the FLIR ${ }^{\circledR} \mathrm{E} 8$ thermal imaging camera. The duration at which the flame-front reaches every marker on the specimen is logged, in addition to the duration at which the flame reaches the end of the specimen, referred to as $\mathrm{M}^{\text {end }}$. Also, the duration at which the specimen self-extinguishes is timed and logged. It is important to clarify that the flame-front was not uniform in all cases. In certain specimens, the flame-front was seen to reach a certain section of a marker, whereas, the remaining section does not ignite till after a slightly delayed duration. In such cases, in accordance with the recommendations of the UL94 HBF standard, the timing was performed at the point when the flame reaches a certain marker, regardless of the marker location being not fully ignited. Besides, the mentioned delay in burning duration was of insignificant value, being within less than 2-5 seconds. Furthermore, the fact that five specimens for each panel were tested, further ensures precise results. Also, the fume hood's extraction mechanism in which the entire set-up was placed was turned off prior to conducting each.

\section{RESULTS}

The results presented later include the durations that are elapsed for the flame-front to burn the section of the tested specimen between everytwo markers. Also, the duration required for the entire specimen to ignite completely is provided, referred to as $\mathbf{M}^{\text {End }}$, in addition to the duration required for the flame to fully extinguish, referred to as ET. It should be noted that Both $\mathrm{M}^{\text {End }}$ and ET are calculated, without including $\mathrm{M}^{1}$, meaning that:

$$
\begin{gathered}
M^{\text {End }}(\text { Min })=\left(M^{1} \text { to } M^{2}\right)+\left(M^{2} \text { to } M^{3}\right)+\left(M^{3} \text { to } M^{4}\right)+\left(M^{4}\right. \text { to } \\
\text { full ignition }) \\
\text { Where, } \\
\left(M^{1} \text { to } M^{2}\right) \text { is the duration of incineration from } M^{1} \text { to } M^{2} . \\
\left(M^{2} \text { to } M^{3}\right) \text { is the duration of incineration from } M^{2} \text { to } M^{3} . \\
\left(M^{3} \text { to } M^{4}\right) \text { is the duration of incineration from } M^{3} \text { to } M^{4} . \\
\left(M^{4} \text { to full ignition }\right) \text { is the duration of incineration from } \\
M^{4} \text { to the end. }
\end{gathered}
$$

And,

$E T($ Min $)=($ Elapsed duration for the tested specimen to extinguish)-(MEnd)

It should be noted thatin certain cases where the flame had self-extinguished, the specimen was re-ignited. The tested specimens that have undergone re-ignition have been indicated by the term (RI) in the tables showing timing results, displayed later. The timing process, in this case, continued normally. However, in other cases where the specimen had self-extinguished for a second time, the specimen was not re-ignited. In the shown later tables, this is indicated by $(\mathrm{X})$, meaning that the sample had extinguished before reaching the corresponding marker. In this case, ET represents the self-extinguishing time for the partially burned specimens. Furthermore, the pace at which the flame-front had burnt through the section of the tested specimen from $\mathrm{M}^{1}$ to $\mathrm{M}^{4}$ has been calculated in units of $\mathrm{mm} /$ minutes. As the tested specimens are $76.2 \mathrm{~mm}$ ( 3 inches) in length and the elapsed time of the fire front in logged in minutes, the pace of burning $(\mathrm{PB})$ is calculated as:

$P B(\mathrm{~mm} / \mathrm{min})=\frac{76.2}{(\text { M1 to } M 2)+(\text { M2 to } M 3)+(\text { M3 to } M 4)}$

An example of the testing procedure for one of the tested samples is shown inTable 1, in this case for a PU/PCM150 specimen. The corresponding thermal images are also shown inTable 2. It is worthy to note that all of the captured images were used for the analysis of the results obtained.

Table 1: Example of testing procedure for PU/PCM150, at 10 sec. intervals.

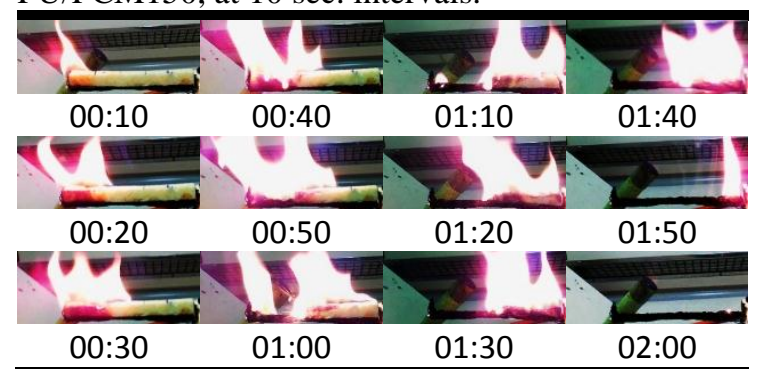

Table 2: Example of thermal images during testing for the PU/PCM150.

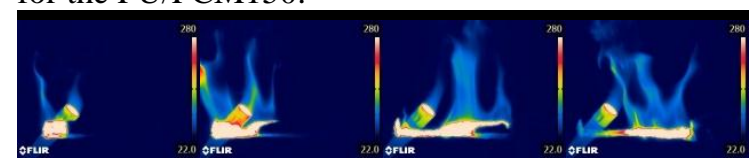

$00: 10$

$00: 40$

$01: 10$

01:40

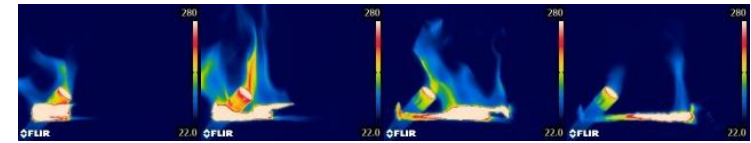

00:20

$00: 50$

01:20

$01: 50$

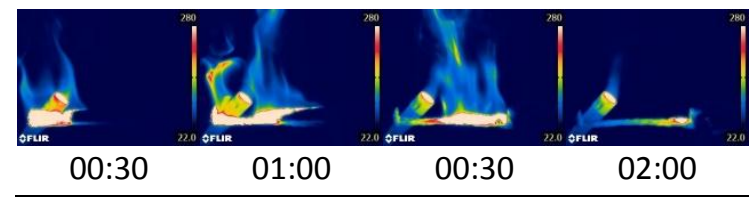

For all the tested specimens, the logged duration required for the flame-front to travel between the markers is shown in Table 3, in addition to ET, PB and averages. Visual examination during the testing procedure reveals that, for the PU specimens, no flaming drippings were observed which indicates that the specimens are fully burnt without melting. All the specimens had self-extinguished and required reincineration.Trivial amounts of black smoke were seen during the ignition of the tested specimens and 
no afterglow was observed after extinguishing.Except for specimen 5, the PU specimens have provided intact remains. In the case of the PU/PCM150 specimens, similarly, no ignited drippings or smoke was observed. However, all the specimens were fully ignited without the need of reignition and exhibited near-complete degradation without remains.This is also true for the PU/PCM300 specimens.

Table 3: Logged timing for flame-front movement on the tested specimens.

\begin{tabular}{|c|c|c|c|c|c|c|c|}
\hline & $\begin{array}{l}\text { Start to } \\
\mathbf{M}^{1} \\
\text { (Min.) }\end{array}$ & $\begin{array}{l}\mathbf{M}^{1} \text { to } \\
\mathbf{M}^{2} \\
\text { (Min.) }\end{array}$ & $\begin{array}{c}\mathbf{M}^{2} \text { to } \\
\mathbf{M}^{3} \\
\text { (Min.) }\end{array}$ & $\begin{array}{c}\mathbf{M}^{3} \text { to } \\
\mathbf{M}^{4} \\
\text { (Min.) }\end{array}$ & $\begin{array}{c}\mathbf{M}^{\text {End }} \\
\text { (Min.) }\end{array}$ & $\begin{array}{c}\text { ET } \\
\text { (Min.) }\end{array}$ & $\underset{(\mathrm{mm} / \mathrm{min} \text {. })}{\mathbf{P B}}$ \\
\hline \multicolumn{8}{|c|}{ PU specimens(RI) } \\
\hline Specimen 1 & $00: 23$ & $00: 24$ & $00: 25$ & 00:39 & $01: 37$ & $02: 33$ & 51.84 \\
\hline Specimen 2 & $00: 42$ & $00: 32$ & $x$ & - & $00: 32$ & $00: 51$ & 142.88 \\
\hline Specimen 3 & $00: 30$ & $00: 19$ & $00: 19$ & $00: 51$ & $02: 08$ & 01:51 & 51.49 \\
\hline Specimen 4 & $00: 26$ & $00: 18$ & $00: 17$ & $00: 24$ & $01: 23$ & $02: 42$ & 77.49 \\
\hline Specimen 5 & $00: 32$ & $00: 35$ & $00: 14$ & $00: 25$ & 01:39 & $02: 56$ & 61.95 \\
\hline Average & 30:36 & $25: 36$ & $18: 45$ & $34: 45$ & 01:27 & $02: 10$ & 77.13 \\
\hline \multicolumn{8}{|c|}{ PU/PCM150 specimens } \\
\hline Specimen 1 & $00: 10$ & $00: 15$ & $00: 18$ & $00: 12$ & $01: 10$ & 01:21 & 101.60 \\
\hline Specimen 2 & $00: 11$ & 00:19 & $00: 16$ & $00: 17$ & 01:21 & 02:01 & 87.92 \\
\hline Specimen 3 & $00: 21$ & $00: 26$ & $00: 29$ & $00: 12$ & $01: 18$ & $01: 45$ & 68.04 \\
\hline Specimen 4 & $00: 17$ & $00: 16$ & $00: 11$ & 00:06 & $00: 42$ & 01:32 & 138.55 \\
\hline Specimen 5 & $00: 20$ & $00: 19$ & $00: 16$ & 00:11 & 01:02 & 01:24 & 99.39 \\
\hline Average & 00:15 & $00: 19$ & $00: 18$ & $00: 11$ & 01:06 & $01: 36$ & 99.10 \\
\hline \multicolumn{8}{|c|}{ PU/PCM300 specimens } \\
\hline Specimen 1 & 00:06 & 00:06 & 00:07 & $00: 17$ & 00:41 & $01: 12$ & 152.40 \\
\hline Specimen 2 & $00: 06$ & $00: 08$ & $00: 10$ & 00:07 & $00: 52$ & $01: 18$ & 182.88 \\
\hline Specimen 3 & $00: 05$ & 00:07 & 00:06 & 00:06 & $00: 51$ & 01:11 & 240.63 \\
\hline Specimen 4 & $00: 08$ & 00:06 & 00:06 & 00:07 & $00: 42$ & 01:11 & 240.63 \\
\hline Specimen 5 & $00: 10$ & 00:05 & $00: 12$ & $00: 15$ & $00: 59$ & $01: 24$ & 142.88 \\
\hline Average & 00:07 & 00:06 & $00: 08$ & $00: 10$ & $00: 49$ & $01: 15$ & 191.88 \\
\hline
\end{tabular}

\section{COMPARATIVE ANALYSIS AND DISCUSSION}

Comparison of the PU, PU/PCM150 and $\mathrm{PU} / \mathrm{PCM} 300$ specimens is carried to determine the influence of certain amounts of PCMs on the fireretardation properties. The mentioned earlier visual remarks, in section5, indicate that as PCMs are added to PU foam, the severity of incineration had increased which resulted in the specimens burning completely with no remains and smoke. To achieve a detailed comprehension of this, calculated PB values are used. The $P B$ value is significant as it shed light on the ability of the tested materials to impede or encourage flaming under conditions of being ignited. Hence, specimens with less PB value indicate better resistance to fire in comparison with these with higher PB value.It is important to note that the PB value is commonly used to achieve official classifications of fire-retardation of materials, however, in the present study, it is utilized as a form of comparison between the various tested specimens. A comparison of the average $\mathrm{PB}$ values is presented in Figure 6(A). It is apparent that the amount of added PCM has a significant impact. The PU specimens, that contain no PCM, were seen to average a PB value of 77.13 $\mathrm{mm} / \mathrm{min}$, whereas theaddition of an amount of 150 $\mathrm{ml}$ of PCM, in the PU/PCM150 specimen, has resulted in faster burning by a $128.49 \%$ (corresponding to a PB value of $99.10 \mathrm{~mm} / \mathrm{min}$ ). An additional amount of PCM in the same quantity, represented by the PU/PCM300, results in an additional increase of $148.79 \%$ in terms of the speed of burning (corresponding to a PB value of 191.88 $\mathrm{mm} / \mathrm{min}$ ). Hence, it can be inferred that the addition of PCMs to amalgams is disadvantageous in terms of fire-retardation. Figure 6(B) showsthe correlation between PCM amount and PB.

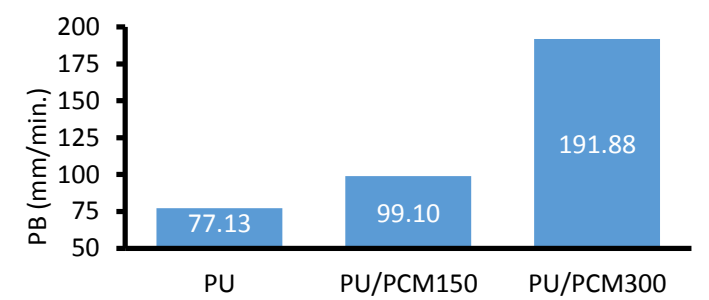

(A)

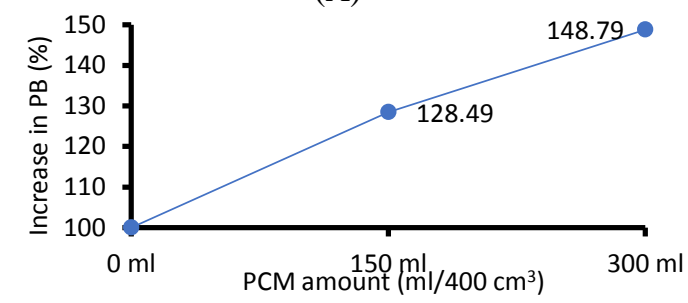

(B)

Figure 6: (A) Average PB values. (B) Influence of PCM amount on PB value.

The duration at which the ignited specimens would tend to self-extinguish is an important factor in terms of fire-retardation. The extinguishing duration, in the present study, is calculated as the time elapsed from the point at which the tested specimen is fully ignited to the point where the flame is completely extinguished, and, referred to as ET. A low ET value can indicate good fireretardation in cases where remains are created as this would indicate that the materials were able to create a charred layer which self-extinguishes flames. However, in a case such a this presented in the study, no remains were present. Hence, a low ET duration indicates that the materials have been rapidly degraded to the point of complete incineration, thus, poor fire-retardation properties. Figure 7(A) shows a comparison between the average values recorded for the tested specimens.It can be seen that ET is reduced as the amount of $\mathrm{PCM}$ is increased. Comparing the ET values of the PU/PCM150 specimensto this of the PU specimens, 
it is seen that the ET duration is reduced by 00:34 min (corresponding to 01:36 min.). Furthermore, in the case of the PU/PCM300 specimensthe ET duration is further reduced by 00:55 $\mathrm{min}$ (corresponding to 01:15 $\mathrm{min}$.). The degree of influence of the amount of amalgamated PCM on the reduction of ET, in comparison with the ET of the PU specimens, is expressed in percentage of the ET for the PU specimens in Figure 7(B). Hence, it may be inferred that increasing the amount of PCM within PU foam would result in faster degradation.It may be worthy to note that it can be observed that there is a partial correlation between the ET values and this of PB. In the PU, PU/PCM150 and PU/PCM300 specimens, it is clear that where PB increases, ET decreases. Meaning that, as expected, the faster the flame ignites the specimens, the faster the self-extinguishing will occur.The intensity of the flame as it passes throughout the specimens is an indicator of the tendency of the tested specimens to further induce flaming. In specimens with relatively good fire-retardation, the intensity of the flame would be expected to be less than this in a specimen with poor fire-retardation properties. This can be assessed in terms of flame properties such as high of the flame in relation to the spread of its base in addition to its temperature. To shed light on the mentioned aspect, thermal images were captured throughout the entire testing procedure.

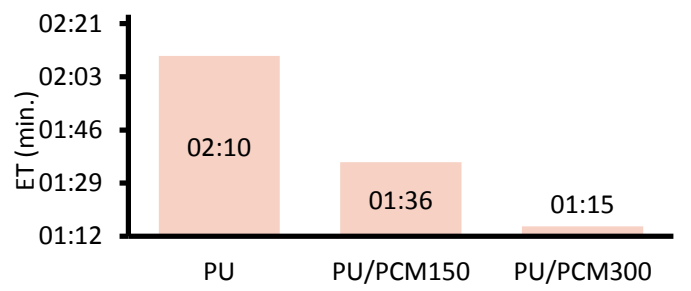

(A)

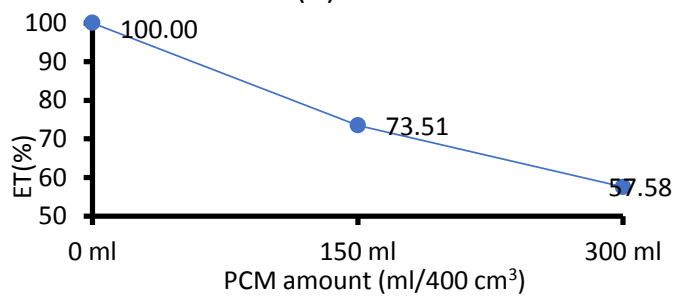

(B)

Figure 7: (A) ET values. (B) Effect of PCM amount on ET duration.

In regards to the PU, PU/PCM150 and PU/PCM300 specimens, there seems to be no apparent difference in the temperature of the ignited section of the specimens as the thermal images indicate that in all three specimens, the mentioned section's temperature was in excess of $280{ }^{\circ} \mathrm{C}$, which is the maximum readable temperature of the utilized thermal camera's range of temperatures. However, it can be observedthat the flames engulfing the PU/PCM300 specimens are of a slightly higher temperature than these engulfing the PU/PCM150 specimens which are in turn higher than the flames affecting the PU specimens, which implies that the amount of PCMs can intensify the burning flames.This is in line with the mentioned earlier findings. Also, correspondingly, the flames in the case of the PU/PCM300 specimens can be seen to be of relatively larger width throughout the entire height of the flame, where, it is of a less width at the upper section in the case of the PU/PCM150 specimens.

\section{CONCLUSIONS}

Throughout the earlier presented fireretardation testing, it is evident that the inclusion of PCM within the structure of PU foam can be disadvantageous in terms of fire-retardancy. As PCM is added, PU foams seem to be more prone to the effects of flames. The inherent flammability is seen to intensify. Also, it is apparent that the amount of PCM can correlate to this. As more PCM is included, the fire-retardancy properties worsen correspondingly. The negative effects are manifested as an apparent increase in the pace of fire, meaning the materials would burn more rapidly. Also, self-extinguishing due to complete degradation is observed to occur at a shorter duration. Furthermore, in terms of burn remains, as PCMs are added, the intensified flames result in full cremation. This impedes the creation of a charred coating layer that can limit the effect of flames. The mentioned findings imply that encapsulation of PCM in PU foam would require a form of firetreatment to ensure that PU/PCM-based thermal insulation can perform within standard safety regulation. It is possible, however, that amalgamation of other materials, including natural materials, can counter the negative effect of PCMs, thus, reducing treatments.Based on the mentioned findings, it can be recommended that in the case of using PCM as a method to enhance PU foam, precautions must be taken to eliminate possible firerisks. For instance, low-cost fire-retardant materials such as ash, sand and plant-seeds can be added to PU mixtures to decrease the pace at which such mixtures would burn. Also, micro-encapsulation of the PCM content using fire-retardant polymers can significantly improve the overall fire-retardation of a PU/PCM mixture. Furthermore, a physical separation can be made between the PU and PCM segments in an insulation through macroencapsulating of the PCM as a layer combined with the PU foam. This would allow for the isolation of the PCM content, thus, eliminating fire-risks. Other types of PCMs, such as salt-hydrates can be useful in this regard as they can be inherently fireretardant. It is evident that this can be a possible area for further research to facilitate safe utilization of PCMs. 


\section{ACKNOWLEDGMENTS}

The authors wish to acknowledge the Egyptian ministry of higher education for funding the work presented in this article as part of a jointsupervision $\mathrm{PhD}$ programme. The authors also extend their thanks and appreciation to DrNicholas Tucker from the University of Lincoln for providing assistance and facilitating the use of equipment and resources essential for the creation of this work.

\section{REFERENCES}

[1] Shanghai Shuode Building Material Co., Ltd. Pu Foam Price Listwww.alibaba.com

[2] Dongguan Dihui Foam Co..Ltd Low Price Anti Bacterial Polyurethane Foam Sheet www.alibaba.com

[3] Reinerte S, Kirpluks M and Cabulis U 2019 Thermal degradation of highly crosslinked rigid PU-PIR foams based on high functionality tall oil polyol Polymer Degradation and Stability $16750-7$

[4] Yang H, Yu B, Song P, Maluk C and Wang H 2019 Surface-coating engineering for flame retardant flexible polyurethane foams: A critical review Composites Part B: Engineering 176107185

[5] Cho J H, Vasagar V, Shanmuganathan K, Jones A R, Nazarenko S and Ellison C J 2015 Bioinspired Catecholic Flame Retardant Nanocoating for Flexible Polyurethane Foams Chem. Mater. 27 6784-90

[6] Gómez-Fernández S, Günther M, Schartel B, Corcuera M A and Eceiza A 2018 Impact of the combined use of layered double hydroxides, lignin and phosphorous polyol on the fire behavior of flexible polyurethane foams Industrial Crops and Products 125 346-59

[7] Gómez-Fernández S, Ugarte L, Calvo-Correas T, PeñaRodríguez C, Corcuera M A and Eceiza A 2017 Properties of flexible polyurethane foams containing isocyanate functionalized kraft lignin Industrial Crops and Products 100 51-64

[8] Tian H, Yao Y, Zhang S, Wang Y and Xiang A 2018 Enhanced thermal stability and flame resistance of rigid polyurethane-imide foams by varying copolymer composition Polymer Testing 67 68-74

[9] Liu L and Wang Z 2018 High performance nano-zinc amino-tris-(methylenephosphonate) in rigid polyurethane foam with improved mechanical strength, thermal stability and flame retardancy Polymer Degradation and Stability $15462-72$

[10] Liu L and Wang Z 2018 Synergistic effect of nano magnesium amino-tris-(methylenephosphonate) and expandable graphite on improving flame retardant, mechanical and thermal insulating properties of rigid polyurethane foam Materials Chemistry and Physics 219 $318-27$

[11] Wu N, Niu F, Lang W, Yu J and Fu G 2019 Synthesis of reactive phenylphosphoryl glycol ether oligomer and improved flame retardancy and mechanical property of modified rigid polyurethane foams Materials \& Design 181107929

[12] Shi X, Yang P, Peng X, Huang C, Qian Q, Wang B, He J, Liu X, Li Y and Kuang T 2019 Bi-phase fire-resistant polyethylenimine/graphene oxide/melanin coatings using layer by layer assembly technique: Smoke suppression and thermal stability of flexible polyurethane foams Polymer 170 65-75

[13] Pan Y, Liu L, Cai W, Hu Y, Jiang S and Zhao H 2019 Effect of layer-by-layer self-assembled sepiolite-based nanocoating on flame retardant and smoke suppressant properties of flexible polyurethane foam Applied Clay Science $168230-6$

[14] Kim Y S, Davis R, Cain A A and Grunlan J C 2011 Development of layer-by-layer assembled carbon nanofiber-filled coatings to reduce polyurethane foam flammability Polymer 52 2847-55

[15] Carosio F, Ghanadpour M, Alongi J and Wågberg L 2018 Layer-by-layer-assembled chitosan/phosphorylated cellulose nanofibrils as a bio-based and flame protecting nano-exoskeleton on PU foams Carbohydrate Polymers 202 479-87

[16] Mestry S, Kakatkar R and Mhaske S T 2019 Cardanol derived $\mathrm{P}$ and $\mathrm{Si}$ based precursors to develop flame retardant PU coating Progress in Organic Coatings 129 $59-68$

[17] Han W, Ge C, Zhang R, Ma Z, Wang L and Zhang X 2019 Boron nitride foam as a polymer alternative in packaging phase change materials: Synthesis, thermal properties and shape stability Applied Energy 238 942-51

[18] Zhu Y, Qin Y, Liang S, Chen K, Wei C, Tian C, Wang J, Luo X and Zhang L 2019 Nanoencapsulated phase change material with polydopamine-SiO2 hybrid shell for tough thermo-regulating rigid polyurethane foam Thermochimica Acta 676 104-14

[19] Amaral C, Vicente R, Ferreira V M and Silva T 2017 Polyurethane foams with microencapsulated phase change material: Comparative analysis of thermal conductivity characterization approaches Energy and Buildings 153 392-402

20] Michel B, Glouannec P, Fuentes A and Chauvelon P 2017 Experimental and numerical study of insulation walls containing a composite layer of PU-PCM and dedicated to refrigerated vehicle Applied Thermal Engineering 116 382-91

[21] Aydın A A and Okutan H 2013 Polyurethane rigid foam composites incorporated with fatty acid ester-based phase change material Energy Conversion and Management 68 74-81

[22] Tinti A, Tarzia A, Passaro A and Angiuli R 2014 Thermographic analysis of polyurethane foams integrated with phase change materials designed for dynamic thermal insulation in refrigerated transport Applied Thermal Engineering 70 201-10

[23] Yang C, Fischer L, Maranda S and Worlitschek J 2015 Rigid polyurethane foams incorporated with phase change materials: A state-of-the-art review and future research pathways Energy and Buildings 87 25-36

[24] Serrano A, Borreguero A M, Garrido I, Rodríguez J F and Carmona M 2016 Reducing heat loss through the building envelope by using polyurethane foams containing thermoregulating microcapsules Applied Thermal Engineering 103 226-32

[25] Serrano A, Borreguero A M, Garrido I, Rodríguez J F and Carmona M 2017 The role of microstructure on the mechanical properties of polyurethane foams containing thermoregulating microcapsules Polymer Testing 60274 82

[26] Amaral C, Pinto S C, Silva T, Mohseni F, Amaral J S, Amaral V S, Marques P A A P, Barros-Timmons A and Vicente R 2020 Development of polyurethane foam incorporating phase change material for thermal energy storage Journal of Energy Storage 28101177

[27] Ahmadi Y, Kim K-H, Kim S and Tabatabaei M 2020 Recent advances in polyurethanes as efficient media for thermal energy storage Energy Storage Materials 30 74-86

[28] Purohit B K and Sistla V S 2018 Studies on solution crystallization of $\mathrm{Na} 2 \mathrm{SO} 4 \cdot 10 \mathrm{H} 2 \mathrm{O}$ embedded in porous polyurethane foam for thermal energy storage application Thermochimica Acta 668 9-18

[29] Du X, Li J, Wang S, Wang H, Cheng X and Du Z 2018 Fabrication and characterization of polyurethane foams containing phase change materials for thermal energy storage Thermochimica Acta 670 55-60 


\section{تأثير المواد متغيرة الطور(PCMs) على خواص مقاومة الحريق لرغوة البولي يوريثين (PU)} المستخدمة للعزل الحرارى متفير الفور

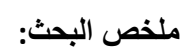

تعتبر رغوة البولى يوريثين (PU)من المواد التى تستخدم بكثرة وبكفاءة فى مجال العزل الحرارى

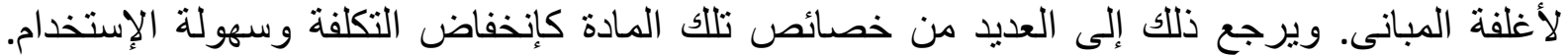

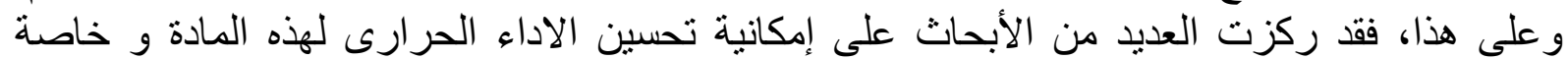

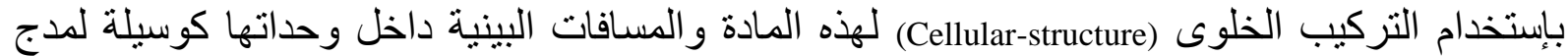

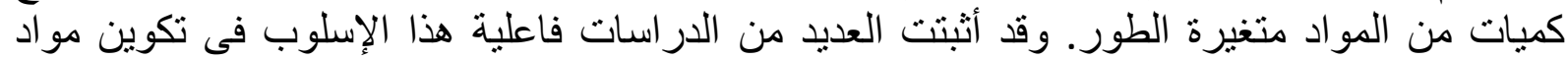

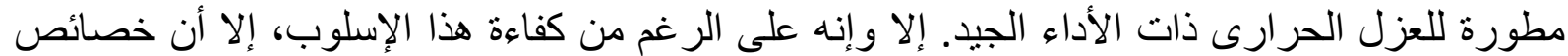

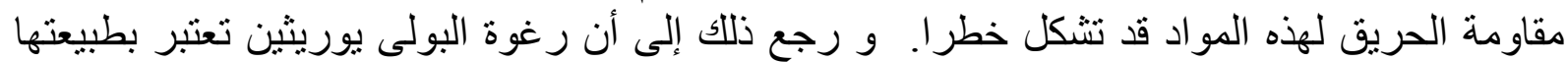

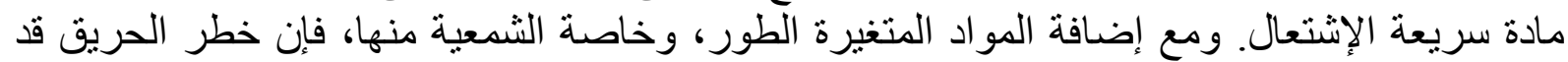

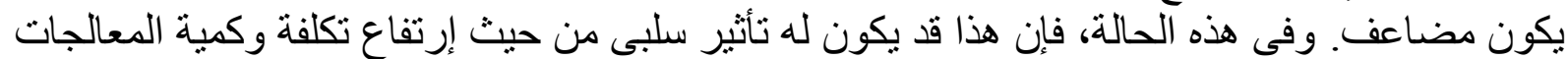

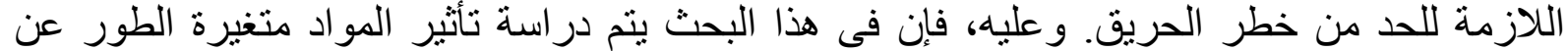

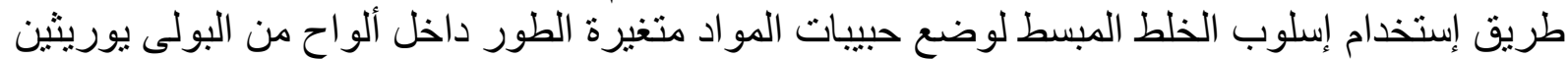

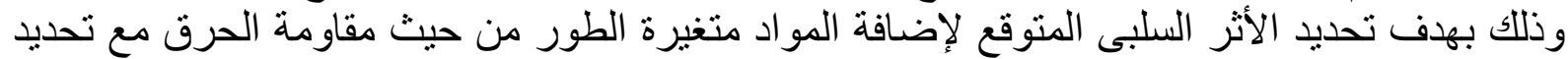

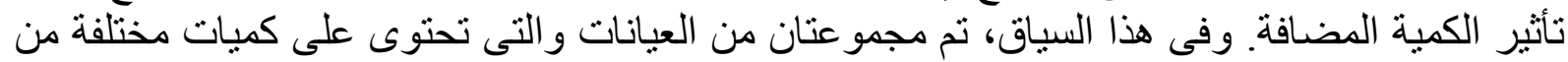

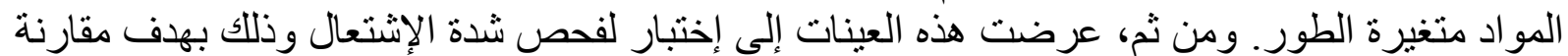

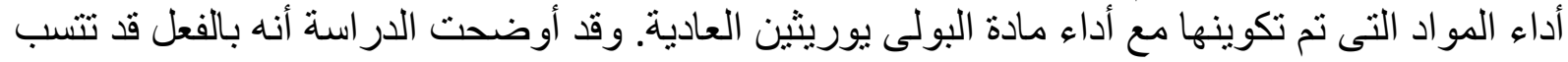

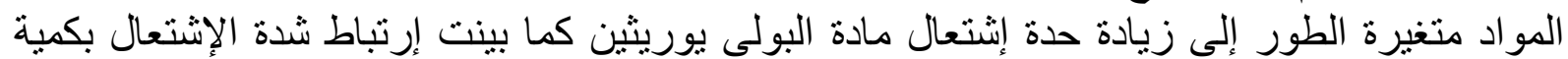
المو اد متغيرة الطور المضافة.

الكلمات المرجعة: رغوة البولى يوريثين، المو اد متغيرة الطور ،كبسو لات المواد متغيرة الطور، إسلوب

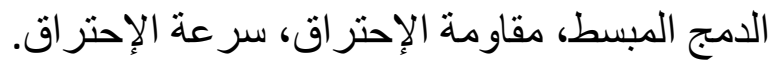

